\title{
Desenvolvimento de centrífuga automática para produção de açúcar de polarização muito alta
}

\author{
Alexsander Saves dos Santos ${ }^{1}$ \\ Caroline Diodato de Toledo ${ }^{2}$ \\ Felipe Fernando Pereira ${ }^{3}$ \\ Jean Soares de Lima ${ }^{4}$
}

\begin{abstract}
RESUMO
Este trabalho tem como objetivo descrever o desenvolvimento do projeto de uma centrífuga automática para açúcar de polarização muito alta, da sigla em inglês VHP (Very High Polarization), e a importância do seu uso na produção de açúcar. O artigo mostra todo o processo de construção, os testes de funcionamento e os cálculos de operações unitárias a fim de encontrar o valor da capacidade da centrífuga. A temática aborda também a análise físico-química de determinação de umidade do açúcar, em que se testou o açúcar VHP produzido pela centrífuga após ser descarregado e antes de passar pelo processo de secagem. Ao término do trabalho, concluiu-se que a centrífuga confeccionada atende a todas as demandas de funcionamento e que o açúcar produzido por ela se encontra dentro dos padrões de umidade.
\end{abstract}

Palavras-chave: Açúcar. Centrifugação. Umidade. Vazão.

\footnotetext{
${ }^{1}$ Graduado em Física pelo Centro Universitário de Votuporanga - UNIFEV e em Pedagogia pela Faculdade da Aldeia de Carapicuíba - FALC. Possui Especialização em Fundamentando a Prática de Ensino do Professor de Matemática pela Universidade Estadual Paulista Júlio de Mesquita Filho - UNESP, Campus de Ilha Solteira. É Mestre em Ciências Ambientais pela Universidade Brasil, Campus de Fernandópolis; professor e pesquisador nos Cursos de Engenharia Química e Medicina da Universidade Brasil, Campus de Fernandópolis, SP, Brasil. E-mail: saves.santos@gmail.com.

${ }^{2}$ Graduanda em Engenharia Química pela Universidade Brasil, Campus de Fernandópolis, SP, Brasil. E-mail: carol_toledo@hotmail.com.

${ }^{3}$ Técnico em Administração pela Escola Técnica Estadual Professor Armando José Farinazzo e Graduando em Engenharia Química pela Universidade Brasil, Campus de Fernandópolis, SP, Brasil. E-mail: felipe.07.fernando.pereira@gmail.com.

${ }^{4}$ Tecnólogo em Química com ênfase em Açúcar e Álcool pelo Instituto Educacional Profissionalizante - IEP, Iturama, MG. É Graduando em Engenharia Química pela Universidade Brasil, Campus de Fernandópolis, SP, Brasil. E-mail: jeanlimananet@ hotmail.com.
} 


\title{
Development of an automatic centrifuge for very high polarization sugar production
}

\begin{abstract}
This project aims to describe the development of the project of an automatic centrifuge for Very High Polarization (VHP) sugar, and the importance of its use in the production of sugar. The article shows the entire process of construction, operational tests and calculations of unitary operations in order to find the value of the centrifuge capacity. The subject also deals with the physical-chemical analysis of sugar moisture determination, where the VHP sugar produced by the centrifuge was tested after being discharged and before going through the drying process. At the end of the assignment it was concluded that the centrifuge manufactured meets all operating demands and that the sugar produced by it is within moisture standards.
\end{abstract}

Keywords: Sugar. Centrifugation. Moisture. Flow.

Artigo recebido em: 12/03/2020

Aceito em: 04/06/2020 


\section{INTRODUÇÃ̃O}

Com a Inglaterra recém industrializada no século XVIII, havia uma grande quantidade de importação de leite e de queijo. Os fazendeiros então foram em busca de melhorias para assim aumentar não só a produção, mas para atingir um aumento consecutivo dos lucros. $\mathrm{O}$ processo utilizado naquela época era o desnato de leite via repouso - o leite permanecia em galões por $24 \mathrm{~h}$, assim a nata se aglomerava na superfície e depois era retirada (BASTOS; AFONSO, 2015).

De acordo com Bastos e Afonso (2015), com o passar dos anos, foram desenvolvidos vários métodos de melhorias para aumentar a produção do leite e, em 1864, o alemão Antonin Prandtl (1842-1909) desenvolveu o primeiro separador mecânico que usava a força centrífuga. Ele utilizava dois baldes presos a hastes que eram conectadas a um rotor manuseado manualmente. O equipamento armazenava o leite desnatado no fundo do balde e conservava a nata na superfície, assim, depois de um tempo ele era parado e a nata era retirada da superfície.

Alguns anos depois, em 1879, Karl Gustaf Patrik de Laval (1845-1913), engenheiro mecânico sueco, criou um sistema funcional para a separação do leite, que utilizaria um sistema contínuo no qual poderia ser retirada a nata e que, em seguida, era higienizado sem interromper o processo, destinado como sistema de centrifugação do tipo cesta. Dez anos depois, o alemão Clemens von Becholsheim (1852-1930) introduziu melhorias para o separador de Laval, os chamados "pratos alfa". Esse sistema dividia o leite em finas camadas, o que aumentava a eficiência da separação (BASTOS; AFONSO, 2015, p. 754).

Ao final do século XIX, quando da produção dos primeiros modelos, os fabricantes promoveram diversas melhorias nas centrífugas, tais como os materiais utilizados na fabricação, o sistema de engrenagem, o aumento da segurança operacional, a aparência e os materiais utilizados no acabamento. A Figura 1 (a seguir) evidencia os primeiros modelos e as melhorias nas centrífugas. 
Figura 1: Centrífuga a manivela com 4 tubos (1910); Centrífuga a manivela com proteção na região de rotação (1912); Centrífuga movida a manivela, com tampa protetora - uma revolução no design (1913)

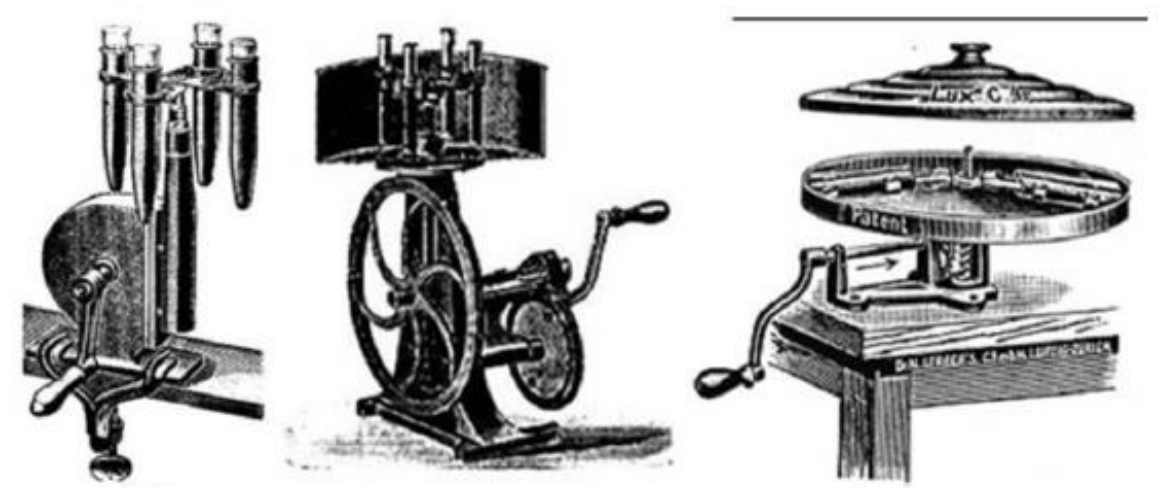

Fonte: Bastos e Afonso (2015).

“A centrifugação pode ser entendida como uma operação de separação mecânica que permite acelerar o fenômeno de decantação, por meio da imposição do movimento de rotação de uma suspensão líquido-partícula" (CREMASCO, 2014, p. 190). Portanto, a centrifugação consistente em separar materiais através da força mecânica, dessa forma isolando um material do outro em diferentes recipientes.

Segundo Bastos e Afonso (2015, p. 754), a “centrífuga é o equipamento que submete uma amostra a uma trajetória circular em torno de um eixo fixo. O princípio de funcionamento é simples: um rotor, no qual ficam conectados os tubos contendo as amostras, é acoplado ao eixo central".

Conforme afirma Foust (2013), a separação mecânica de uma solução ou de uma mistura, ambas homogêneas, necessita de uma transferência, preferencialmente de um constituinte para uma segunda fase, em que possam ser fisicamente separados da mistura residual. Este efeito pode ser ilustrado pela desumidificação do ar pelo congelamento ou pela condensação de uma parte da umidade, ou até mesmo pelo uso de um solvente líquido que seja insolúvel no material que não foi extraído.

Assim, pode estar envolvida qualquer operação de duas fases que tenha uma distribuição preferencial dos constituintes e em que possam ser separadas do restante facilmente. Entretanto, é possível que seja difícil separar duas fases sólidas (um líquido ou um gás), ou um sólido (que geralmente são separados com facilidade), dois líquidos com 
densidades quase iguais e sem tensão interfacial que podem ser resistentes aos meios práticos de separação, a não ser que se altere uma das fases (FOUST, 2013).

A separação de particulados é muito importante, pois, além de obter o produto desejado, ela evita o desperdício de materiais de altos valores e controla a poluição do ambiente. São encontrados diferentes tipos de equipamentos para a separação de partículas: os separadores centrífugos (centrífugas, ciclones e hidrociclones) e os gravitacionais (câmera de poeira e elutriadores). Todos eles têm como princípio a decantação, “[...] que se refere à deposição de particulado ou a sua captura, tendo como base o conhecimento da sua velocidade terminal"' (CREMASCO, 2014, p. 181).

A centrífuga é o equipamento onde é realizada a centrifugação e nela a força centrífuga separa as partículas do eixo de rotação. A centrifugação é baseada na separação de partículas pela diferença de tamanho, de massa específica, ou de ambos. A trajetória da partícula da centrífuga tubular permite que o valor do diâmetro da partícula, captada na parede do equipamento, seja especificado, independente de qual seja o tipo de centrifugação (CREMASCO, 2014, p. 181).

Os ciclones e hidrociclones são equipamentos usados para a separação dos particulados que estão presentes em corrente gasosa ou em corrente líquida (no caso dos hidrociclones). Esses equipamentos são representados numa construção de cone cilíndrico e são classificados como separadores centrífugos (CREMASCO, 2014). A Figura 2 apresenta o esquema de um hidrociclone.

Figura 2: Correntes de escoamento em um hidrociclone

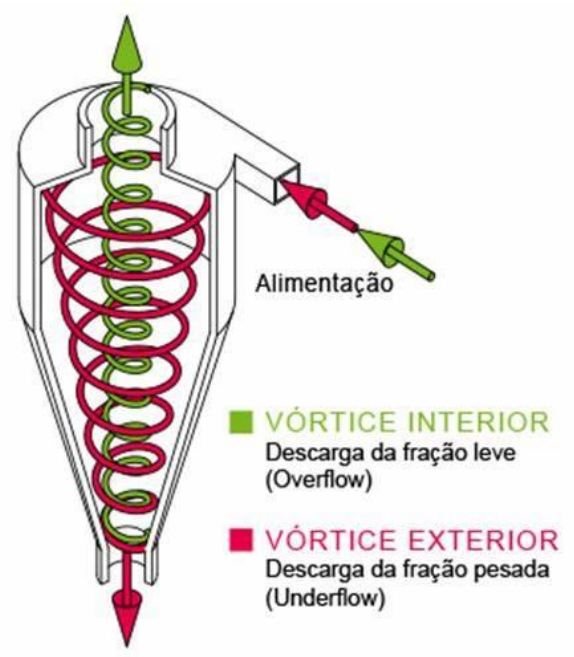

Fonte: AKW Equipment + Process Design (Acesso: 07 mai. 2020). 
“A Elutriação refere-se à operação de separação baseada na diferença entre a velocidade média do fluido e a velocidade terminal da partícula" (CREMASCO, 2014, p. 184). É um processo de separação de partículas em que um fluxo vindo de um líquido separa as partículas sólidas, devido as suas densidades, e as posiciona em diferentes níveis, podendo transportá-las para fora do tanque mediante o controle do fluxo; processo que consiste numa sedimentação ao contrário.

A diferença entre o tempo de permanência de uma determinada partícula é levada em consideração no processo de separação mecânica no interior da câmara de poeira. Esse processo é baseado na diferença entre o tempo de permanência da partícula, em corrente gasosa, e o tempo de queda em uma coluna de separação. O tempo de permanência também pode ser entendido como tempo de trânsito em que essa partícula atravessou tal coluna (CREMASCO, 2014).

Centrífugas são de extrema importância para indústrias e seu uso pode ser feito em:

- Destilarias (álcool anidro, hidratado e neutro);

- Fecularias (amidos derivados de batata, milho, mandioca etc.);

- Produção de óleos minerais, vegetais, combustíveis e lubrificantes de motores

- Na indústria de laticínios nos processos de: desnatamento, clarificação, degerminação, padronização, produtos derivados do leite;

- Na indústria química: álcool graxo, látex, corantes naturais, substâncias perfumadas e aromáticas;

- No tratamento de efluentes industriais (efluentes urbanos, efluentes em fábrica de papel, de indústria química, água de lavagem de legumes, lodo excedente da indústria de alimentos);

- Na indústria farmacêutica: medicamentos de plantas, antibióticos, sangue humano, insulina, vacinas, morfina.

E, em especial, no processo de produção do açúcar, no qual a centrifugação pode ser feita em duas etapas: contínua e descontínua. De acordo com a USITEP (2017), na etapa descontínua, os cristais de açúcar possuem tamanho aproximado de 0,5 mm envolvidos numa película de mel. Ao centrifugar, há a separação desse mel, que vai para o cozimento, e o açúcar bruto é enviado ao secador de açúcar. Já na etapa contínua, os cristais tem aproximadamente 0,2 $\mathrm{mm}$ e melaço. Quando centrifugados, os cristais são separados do melaço e utilizados como núcleo de cozimento. O melaço é enviado para a produção de álcool. 
Em se tratando de fabricação, ganha destaque o açúcar destinado ao consumo humano e o direcionado ao setor da indústria alimentícia. Uma pequena parcela da produção do açúcar brasileiro é destinada ao comércio interno (37\%) e distribuído para as indústrias de atacado e varejo. Para o mercado externo, é exportado o açúcar de polarização muito alta, da sigla em inglês VHP (Very High Polarization), que é usado para insumo no processo de refinação.

O açúcar VHP é o mais exportado pelo Brasil, possuindo mais claridez que o açúcar demerara e apresentando cristais amarelados. Utiliza-se anidrido sulfuroso no seu branqueamento (MACHADO, 2012). Segundo Ribeiro (2003), esse tipo de açúcar é produzido naturalmente, sem adicionar produtos químicos na sulfitação. A produção desse açúcar é muito ampla, pois ele é destinado à produção de açúcares de melhor qualidade através de sua diluição.

Tendo em vista o exposto acima, este projeto apresenta o esboço de um protótipo de equipamento de centrifugação para a produção de açúcar VHP, que opere de maneira eficaz, para que o açúcar produzido atenda ao teor de umidade ideal.

\section{METODOLOGIA}

Esse projeto foi realizado no município de Fernandópolis - SP, sendo baseado no sistema de centrifugação da Usina Coruripe S/A, filial de Carneirinho - MG, situada na fazenda Bom Sucesso S/N, onde se buscou reproduzir um protótipo, em menor escala, da centrífuga automática utilizada na usina para a separação de cristais de açúcar VHP. A Figura 3 mostra as etapas de desenvolvimento do protótipo.

Figura 3: Etapas do projeto

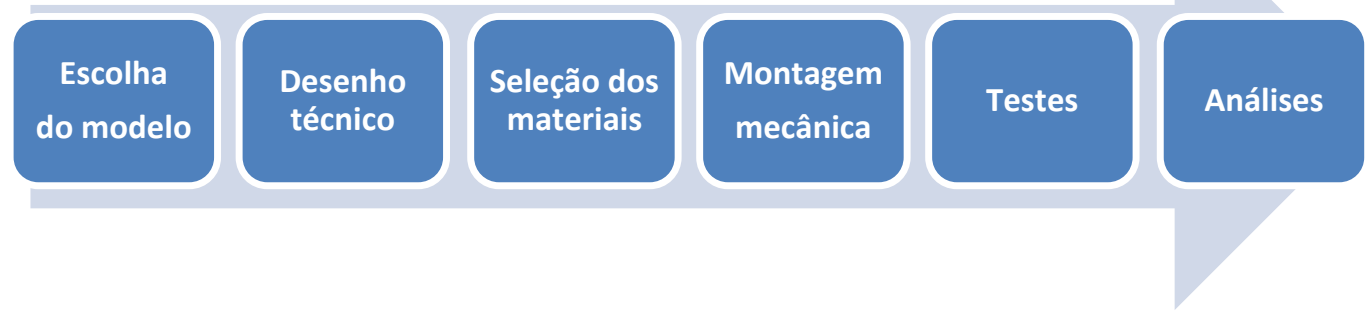

Fonte: Autoria própria. 


\subsection{Montagem da centrífuga}

Os materiais utilizados foram adquiridos através de doações da referida Usina e por meio de recursos próprios, conforme Tabela 1.

Tabela 1: Materiais utilizados no projeto

\begin{tabular}{|c|c|c|c|c|}
\hline Material & Quantidade & Unidade & Valor Unitário (R\$) & Valor Total (R\$) \\
\hline Chapa INOX 3mm & 0,40 & $\mathrm{~m}^{2}$ & 0,00 & 0,00 \\
\hline Conectores elétricos & 12,0 & un & 0,00 & 0,00 \\
\hline Contra-tela INOX & 0,000564 & $\mathrm{~m}^{2}$ & 0,00 & 0,00 \\
\hline Eletrodo 309 & 3,00 & $\mathrm{~kg}$ & 0,00 & 0,00 \\
\hline Eletroválvula & 1,00 & un & 0,00 & 0,00 \\
\hline Fio $4 \mathrm{~mm}$ & 12,0 & $\mathrm{~m}$ & 1,60 & 19,20 \\
\hline Flange 8" & 1,00 & un & 0,00 & 0,00 \\
\hline Haste de INOX $1 "$ & 0,50 & $\mathrm{~m}$ & 0,00 & 0,00 \\
\hline Inversor de frequência & 1,00 & un & 540,00 & 540,00 \\
\hline Mangueira $8 \mathrm{~mm}$ & 5,00 & $\mathrm{~m}$ & 0,00 & 0,00 \\
\hline Metalão 25x25 & 1,00 & $\mathrm{~m}$ & 0,00 & 0,00 \\
\hline Metalão 50x50 & 1,00 & $\mathrm{~m}$ & 0,00 & 0,00 \\
\hline Motor trifásico $1 \mathrm{cv}$ & 1,00 & un & 250,00 & 250,00 \\
\hline Parafuso $3 / 4$ & 2,00 & un & 0,00 & 0,00 \\
\hline Pistão pneumático & 1,00 & un & 100,00 & 100,0 \\
\hline Potenciômetro & 1,00 & un & 50,00 & 50,00 \\
\hline Tarugo NYLON & 0,15 & $\mathrm{~m}$ & 0,00 & 0,00 \\
\hline Tela INOX & 0,000564 & $\mathrm{~m}^{2}$ & 0,00 & 0,00 \\
\hline Tinta spray amarela & 0,9 & $\mathrm{~L}$ & 17,00 & 17,00 \\
\hline Tinta spray branca & 0,9 & $\mathrm{~L}$ & 17,00 & 17,00 \\
\hline Tubo INOX 1" & 1,00 & $\mathrm{~m}$ & 0,00 & 0,00 \\
\hline Tubo INOX 3" & 1,00 & $\mathrm{~m}$ & 0,00 & 0,00 \\
\hline Tubo INOX 6" & 1,00 & $\mathrm{~m}$ & 0,00 & 0,00 \\
\hline Tubo INOX 8" & 1,00 & $\mathrm{~m}$ & 0,00 & 0,00 \\
\hline Total & & & & $\mathrm{R} \$ \mathbf{9 9 3 , 2 0}$ \\
\hline
\end{tabular}

Fonte: Autoria própria. 
As etapas de montagem da centrífuga estão elencadas na Figura 4.

Figura 4: Montagem da centrífuga

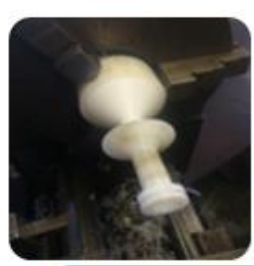

Corte do

tarugo de

nylon e

fabricação do cilindro.

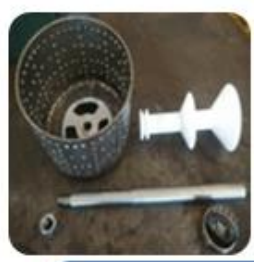

Fabricação do

cesto com furo central
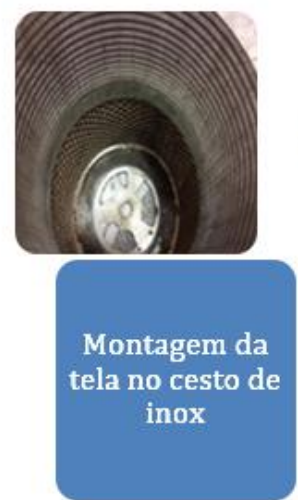

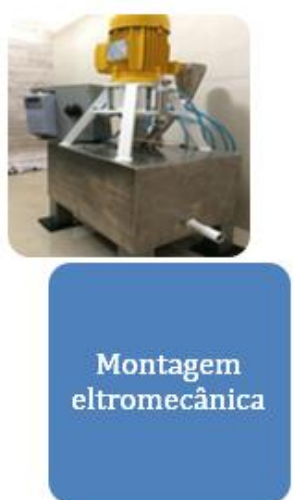

Fonte: Autoria própria.

Para início do processo de fabricação, foi preciso realizar, primeiramente, um corte no tarugo de nylon com 0,15 m de comprimento. Em seguida, ele foi levado ao torno para a fabricação do êmbolo e realização do furo central com $0,015 \mathrm{~m}$ de diâmetro. Cortou-se o tubo de inox de 6" com 0,12 m de comprimento, em que se furou com broca 3/16 mm para a realização do cesto. Foi cortada, também, uma haste de inox com $0,25 \mathrm{~m}$ de comprimento para fabricar o eixo.

Logo após, foram cortadas duas chapas com 0,15 m de diâmetro e em uma delas foi realizado um furo central com $0,015 \mathrm{~m}$ de diâmetro enquanto na outra foi realizado um furo central com 0,10 m de diâmetro para tampar as extremidades do cesto. Cortou-se a tela de inox com 0,47 x $0,12 \mathrm{~m}$ para revestir internamente o cesto. Uma contra-tela com $0,47 \times 0,12$ $\mathrm{m}$ foi usada para servir como suporte para a tela e ambas foram colocadas na calandra para ficarem com o formato cilíndrico do cesto.

Uma chapa de $0,005 \mathrm{~m}$ de espessura com $0,15 \times 0,15 \mathrm{~m}$ foi utilizada para fabricar a base do motor. Em seguida, foi realizada a montagem do cesto, do suporte do motor e do acoplamento.

Foram cortadas duas chapas de $3 \mathrm{~mm}$ de espessura com 0,20 x 0,40 $\mathrm{m}$ e duas chapas de $3 \mathrm{~mm}$ de espessura com 0,20 x 0,40 m para fabricação da base do equipamento. Foi utilizado um tubo de 8 " com $0,25 \mathrm{~m}$ de comprimento e soldou-se no flange de 8 " para realizar a base do cesto.

Acoplou-se o motor ao cesto, realizou-se a instalação elétrica do motor ao inversor de frequência e ajustou-se aos parâmetros de operação. Realizou-se a instalação de um pistão 
pneumático para subir o êmbolo do cesto. No final foi feita a pintura do equipamento com tinta spray na cor branca. A Figura 5 apresenta o projeto finalizado.

Figura 5: Centrífuga finalizada

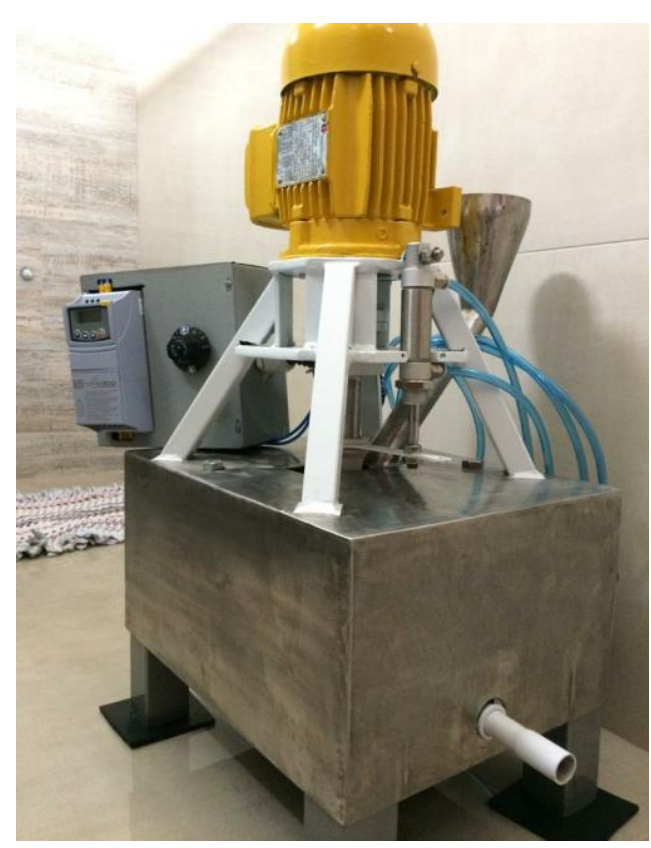

Fonte: Autoria própria.

\subsection{Teste da centrífuga}

Os testes iniciais foram realizados em Carneirinho - MG, no dia 3 de novembro às 22 h. Ao fazer o teste de rotação, o potenciômetro apresentou problema elétrico e foi necessário acessar o IHM (Interface Homem-Máquina) do inversor e desabilitá-lo no parâmetro 221, passando a fazer o controle de rotação no próprio inversor.

Iniciando-se, então, o teste, ligou-se o inversor e em seguida o motor com $20 \mathrm{rpm}$ de rotação. Fez-se o teste do pistão pneumático, elevando a rotação do motor para $70 \mathrm{rpm}$, que é a velocidade de carga, e através do duto de alimentação foi adicionado aproximadamente $1200 \mathrm{ml}$ de massa cozida coletada no processo de cozimento do açúcar VHP da Usina Coruripe.

Após a carga completa do cesto da centrífuga, a rotação foi aumentada para $160 \mathrm{rpm}$. Pode-se observar a separação do mel pobre, que totalizou cerca de $0,32 \mathrm{~L}$. Foi então trocado o reservatório e adicionado $0,1 \mathrm{~L}$ de água a $368,15 \mathrm{~K}$, dando início à lavagem do açúcar. Observou-se o escoamento do mel rico com um volume de $0,18 \mathrm{~L}$. 
Depois da lavagem, aumentou-se a rotação para $180 \mathrm{rpm}$, tendo o pico final da centrifugação. Em seguida, diminuindo a rotação para $20 \mathrm{rpm}$, acionou-se o pistão pneumático para abrir o compartimento de descarga. Finalmente, foi acionado o dispositivo de raspa para retirar o açúcar do cesto, observando um volume de 0,7 L de açúcar VHP. A Figura 6 mostra o açúcar produzido.

Figura 6: Açúcar VHP

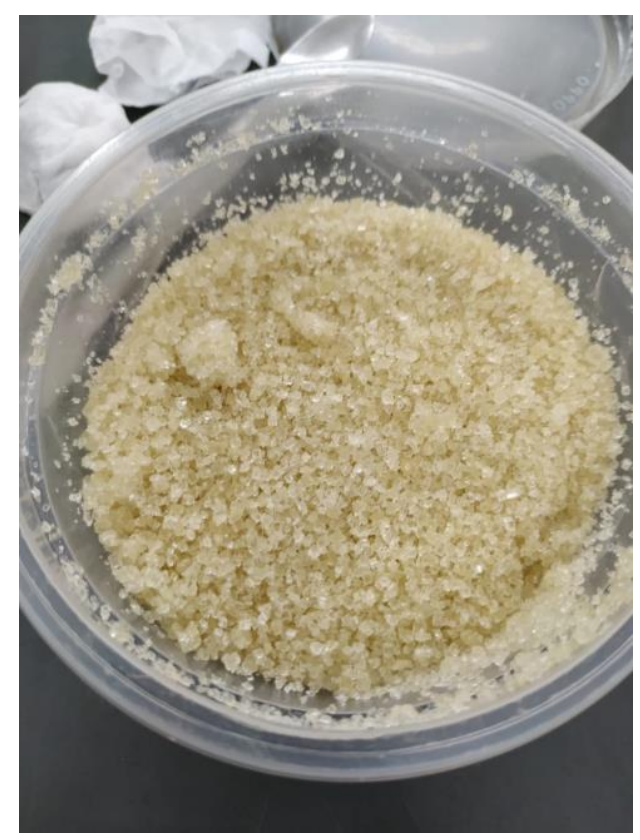

Fonte: Autoria própria.

\subsection{Cálculos de capacidade da centrífuga}

A fim de analisar a capacidade do protótipo, seus resultados foram comparados com os da centrífuga da Usina Coruripe. Realizaram-se diversos cálculos para encontrar as vazões mássicas, volumétricas e velocidades terminal de partícula. Para encontrar a vazão volumétrica da usina utilizou-se a Equação 1:

$$
\mathrm{m}=\rho \cdot Q .
$$

(Equação 1)

Em que m é a vazão mássica dada em $\mathrm{m}^{3} / \mathrm{s}, \rho$ é a massa específica do açúcar em $\mathrm{kg} / \mathrm{m}^{3}$ e Q é a vazão volumétrica em m/s.

Após, realizaram-se os cálculos para encontrar o fator de configuração $\sum$, que considera as dimensões e rotações da centrífuga. Para isso, foi realizado o cálculo para ambas as centrífugas através da Equação 2: 


$$
\Sigma_{1}=\left[\frac{L \cdot N \cdot\left(R^{2}-R o^{2}\right)}{g \cdot \ln \left(\frac{R}{R o}\right)}\right] .
$$

Em que $L$ é o comprimento da centrífuga em m, $N$ é o número de rotações em rps, $R$ é o raio externo da centrífuga em $\mathrm{m}, R o$ é o raio interno da centrífuga e $g$ é a força gravitacional $\mathrm{em} \mathrm{m}^{2} / \mathrm{s}$.

Ao encontrar a vazão volumétrica da centrífuga da usina e sabendo as dimensões das centrífugas, pode-se utilizar tais valores para encontrar a vazão volumétrica do protótipo através da Equação 3:

$$
\frac{Q_{1}}{\sum_{1}}=\frac{Q_{2}}{\sum_{2}}
$$

Finalizando, encontrou-se as velocidades terminais das centrífugas utilizando a Equação 4:

$$
Q=\vartheta_{t \cdot \Sigma}
$$

\subsection{Análise de umidade do açúcar VHP}

No dia 12 de novembro de 2019, foi utilizado o laboratório de uma escola técnica, no município de Fernandópolis - SP, onde se realizou a análise de umidade do açúcar VHP obtido pela centrífuga.

Para iniciar o procedimento de análise de umidade, foi pesado um cadinho em balança analítica e anotou-se o resultado. Em seguida, se pesou 0,02 kg de açúcar e colocou-se o cadinho em estufa pré-aquecida à $373,15 \mathrm{~K}$ durante 3 horas.

Dado o tempo, o cadinho foi retirado e pesado novamente; e com os resultados foi possível calcular a umidade, utilizando a Equação 5:

$$
\frac{100 \times N}{P}=\text { umidade. }
$$

Em que $N$ corresponde ao número de gramas de umidade, que é a perda de massa em grama, dado pela diferença entre o peso do cadinho com a amostra e o peso do cadinho com a amostra após a estufa; e $P$ corresponde ao número de gramas na amostra. 


\section{RESULTADOS E DISCUSSÃO}

A centrifugação é a separação de misturas sólidas-líquidas utilizando a força centrífuga para acelerar o processo de decantação. A etapa de centrifugação é utilizada no processo de produção de açúcar com o objetivo de separar o mel por força centrífuga e reter os cristais de sacarose. A centrifugação é essencial para a obtenção de um produto de qualidade.

Nos testes iniciais, houve dificuldades por conta do transporte e da conservação da massa, pois o esfriamento aumenta a concentração e, sem a agitação lenta, os cristais decantam no recipiente. Para neutralizar esses efeitos, foi necessário conservar a massa em caixa térmica e agilizar o transporte para não haver a decantação. No dia do teste, foi preciso adicionar água à massa devido a seu transporte.

Observa-se no Gráfico 1 que o aumento da massa cozida aumenta proporcionalmente a quantidade de açúcar produzido, visto que isso acontece também com a produção de mel pobre e mel rico e água quente. Chegou-se a resultados próximos dos valores de trabalho de um equipamento industrial, sendo que o equipamento Modelo MAUSA comporta $1800 \mathrm{~kg}$ de massa e produz aproximadamente $900 \mathrm{~kg}$ de açúcar.

Gráfico 1: Resultados dos testes

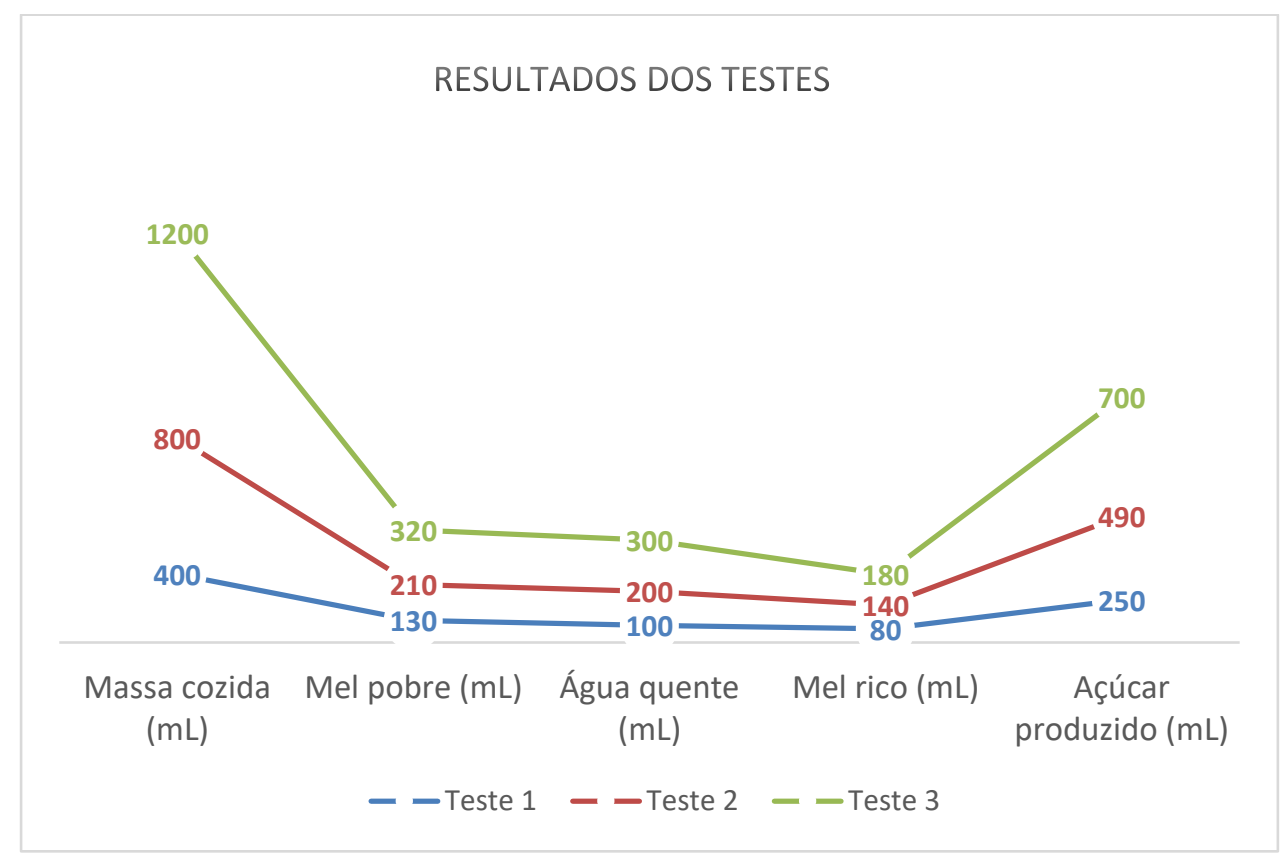

Fonte: Autoria própria. 
Ao analisar a capacidade da centrífuga, comparou-se os valores com os da centrífuga da Usina Coruripe. A usina produz $900 \mathrm{~kg}$ de açúcar VHP por ciclo e 22 ciclos a cada hora. Com essa informação foi possível encontrar um valor de $5,5 \mathrm{~kg} / \mathrm{s}$ de vazão mássica.

Com o valor da sua vazão mássica e o valor da massa específica do açúcar, que de acordo com SUCRANA (2009) é de $1610 \mathrm{~kg} / \mathrm{m}^{3}$, pode-se encontrar a sua vazão volumétrica através da Equação 1.

Em seguida, utilizou-se a Equação 2 para encontrar o fator de configuração da centrífuga, em que foi encontrado o valor de $\sum=1,55 \mathrm{~m}^{2}$ para a usina e $\sum=2,74 \times 10^{-4} \mathrm{~m}^{2}$ para o protótipo.

Com os valores das dimensões das centrífugas e o valor de vazão volumétrica da usina, pode-se achar, com o uso da Equação 3, o valor da vazão volumétrica do protótipo, sendo a vazão igual a $6,03 \times 10^{-7} \mathrm{~m} / \mathrm{s}$.

Achada a vazão volumétrica do protótipo, utilizou-se novamente a equação 1 , desta vez para encontrar o valor de vazão mássica do protótipo, sendo essa vazão igual a $9,70 \times 10^{-4} \mathrm{~kg} / \mathrm{m}^{3}$.

Ao utilizar a Equação 4 para encontrar a velocidade terminal de partículas das centrífugas, chegou-se a resultados aproximadamente iguais para as duas centrífugas. O que mostra que mesmo o protótipo possuindo vazões e dimensões inferiores, apresenta um ótimo funcionamento. Na Tabela 2, pode-se visualizar e comparar os valores encontrados para ambas.

Tabela 2: Valores das centrífugas

\begin{tabular}{c|c|c|c|c|c|c|c|c}
\hline Centrífuga & $\boldsymbol{L}(\mathbf{m})$ & $\boldsymbol{N}(\mathbf{r p s})$ & $\boldsymbol{R}(\mathbf{m})$ & $\boldsymbol{R o}(\mathbf{m})$ & $\sum\left(\mathbf{m}^{2}\right)$ & $\boldsymbol{Q}\left(\mathbf{m}^{3} / \mathbf{s}\right)$ & $\mathbf{m}\left(\mathbf{k g} / \mathbf{m}^{3}\right)$ & $\boldsymbol{\vartheta t}(\mathbf{m} / \mathbf{s})$ \\
\hline Usina & 1,10 & 16,7 & 0,800 & 0,500 & 1,55 & 0,00341 & 5,50 & 0,0022039 \\
\hline Protótipo & 0,110 & 3,30 & 0,0725 & 0,0500 & $2,74 \times 10^{-4}$ & $6,03 \times 10^{-7}$ & $9,70 \times 10^{-4}$ & $2,20 \times 10^{-3}$ \\
\hline
\end{tabular}

Fonte: Autoria própria.

O teste de umidade é importante para determinar a umidade presente no açúcar, para evitar a formação de grumos nos cristais e para que a qualidade do açúcar não seja prejudicada. Com a análise feita no laboratório e através da Equação 5, foi encontrado um valor de umidade de $0,85 \%(\mathrm{~m} / \mathrm{m})$, o que corresponde ao valor ideal que, segundo Cruz (2016), deve variar entre $0,5 \%(\mathrm{~m} / \mathrm{m})$ e $2 \%(\mathrm{~m} / \mathrm{m})$ após o açúcar ser descarregado da 
centrífuga. De acordo com Merheb (2009), esse valor ainda não é o ideal para embalagem, sendo a umidade ideal para o final da produção na faixa entre $0,03 \%(\mathrm{~m} / \mathrm{m})$ e $0,04 \%(\mathrm{~m} / \mathrm{m})$. Por isso, após a centrifugação, esse açúcar deve ser levado para o processo de secagem.

\section{CONCLUSÃO}

Observa-se que o protótipo construído funcionou corretamente, sendo eficiente na produção do açúcar VHP, pois, conforme os cálculos realizados, conseguiu-se comparar os valores de capacidade do protótipo com os valores da centrífuga da usina e, com isso, atingiu-se a velocidade terminal de partículas próximas para ambas as centrífugas, mostrando assim a eficácia de funcionamento do equipamento.

A análise de umidade realizada no laboratório comprovou que o açúcar produzido pelo protótipo atende ao valor ideal de umidade para o açúcar descarregado por uma centrífuga.

\section{REFERÊNCIAS}

BASTOS, A. R.; AFONSO, J. C. Separação sólido-líquido: centrífugas e papéis de filtro. Química Nova, v. 38 n. 5, São Paulo, 2015. Disponível em: http://www.scielo.br/scielo.php?script=sciarttext\&pid=S0100-0422015000500749. Acesso em: 18 out. 2019.

CREMASCO, M. A. Operações unitárias em sistemas particulados e fluidomecânicos. 2. ed. São Paulo: Blucher, 2014.

CRUZ, S. H. Operações Finais: Secagem, classificação e armazenamento do açúcar, 2016. Disponível em: https://edisciplinas.usp.br/mod/resource/view.php?id=1073254. Acesso em: 21 nov. 2019.

FOUST, A. S. Princípios das operações unitárias. Rio de Janeiro: LTC 2013.

MACHADO, S. S. Tecnologia da fabricação de açúcar, 2012. Disponível em: http://proedu.rnp.br/bitstream/handle/123456789/448/tecnolog_da_fabricacao_do_acucar.p df? sequence=5. Acesso em: 02 out. 2019.

AKW EQUIPAMENTOS E PROCESSOS LTDA. Disponível em: https://br.akwauv.de/equipment-process-units/. Acesso: 07 mai. 2020.

MAUSA. Centrífuga automática série mac. 2014. Disponível em: https://docplayer.com.br/11492239-Centrifuga-automatica.html. Acesso em: 10 de set. 2019. 
MERHEB, G. A. Estudo do processo de cristalização de sacarose a partir de soluções provenientes de cana-de-açúcar por resfriamento controlado. 2009. 198 p. Dissertação (Mestrado em Ciências Exatas e da Terra) - Universidade Federal de São Carlos, São Carlos, 2009.

MEZAROBA, S. MENEGUTTI, C. C. GROFF, A. M. Processos de produção do açúcar de cana e os possíveis reaproveitamentos dos subprodutos e resíduos resultantes do sistema. 2010. Disponível em: http://www.fecilcam.br/anais/iv_eepa/data/uploads/9engenharia-da-sustentabilidade/9-04-com-autores.pdf. Acesso em: 20 nov. 2019.

RIBEIRO, Paulo Roberto. A usina de açúcar e sua automação. 2 ed. Araçatuba: SMAR, 2003.

SUCRANA. Peso específico de materiais. 2009. Disponível em: http://www.sucrana.com.br/tabelas/peso-especifico-materiais.pdf. Acesso em: 15 nov. 2019.

USITEP. Centrífugas Açucareiras. 2017. Disponível em: https://usitep.com.br/copiasobre-1. Acesso em: 17 out. 2019. 